\title{
Caracterização eletroforética de proteínas e estabilidade do leite em vacas submetidas à restrição alimentar
}

\author{
Rosângela Silveira Barbosa(1), Vivian Fischer(2), Maria Edi Rocha Ribeiro( ${ }^{(3)}$, Maira Balbinotti Zanela(3), \\ Marcelo Tempel Stumpf ${ }^{(2)}$, Giovani Jacob Kolling ${ }^{(4)}$, Jorge Schafhäuser Júnior ${ }^{(3)}$, Luis Eduardo Barros ${ }^{(5)}$ \\ e Antônio Sílvio do Egito(6)
}

\begin{abstract}
(1)Universidade Federal de Pelotas, Departamento de Zootecnia, Caixa Postal354, CEP 96010-970 Pelotas, RS. E-mail: rosanbarbosa@yahoo.com.br (2)Universidade Federal do Rio Grande do Sul (UFRGS), Departamento de Zootecnia, Avenida Paulo Gama, no 110, CEP 90040-060 PortoAlegre, RS. E-mail: vfried@portoweb.com.br, marcelostumpf2003@yahoo.com.br ${ }^{(3)}$ Embrapa Clima Temperado, Caixa Postal 403, CEP 96001-970 Pelotas, RS. E-mail: maria.edi@cpact.embrapa.br, maira.zanela@cpact.embrapa.br, jorge.junior@cpact.embrapa.br (4)UFRGS, Departamento de Medicina Veterinária Preventiva, Avenida Bento Gonçalves, no 9.090, CEP 91540-000 Porto Alegre, RS. E-mail: giovanikolling@hotmail.com (5)Universidad de La República del Uruguay, Departamento de Patología Clínica de Ruminantes, Lasplaces 1620, Montevideo, Uruguay. E-mail: luisb@adinet.com.uy ${ }^{(6)}$ Embrapa Caprinos e Ovinos, Caixa Postal 145, CEP 62010-970 Sobral, CE. E-mail: egito@cnpc.embrapa.br
\end{abstract}

Resumo - O objetivo deste trabalho foi avaliar os efeitos da restrição alimentar sobre a produção de leite bovino e sobre seu perfil eletroforético de proteínas, bem como relacioná-los à estabilidade do leite pelo teste do álcool. Foram conduzidos dois experimentos com vacas Jersey: no primeiro, avaliou-se o efeito da redução de $40 \%$ na alimentação fornecida a vacas semiconfinadas; no segundo, avaliou-se o efeito da restrição de $30 \%$ do conteúdo de nutrientes digestíveis totais na alimentação de vacas confinadas. As frações proteicas foram determinadas por eletroforese, e sua quantificação por meio de análises de imagens. As amostras de leite foram classificadas conforme estabilidade no teste do álcool a $72^{\circ} \mathrm{GL}$. A restrição alimentar de $40 \%$ a vacas semiconfinadas reduziu a produção de leite, mas não alterou a composição de proteínas lácteas e a estabilidade do leite; neste caso, o leite instável apresentou maiores teores de $\beta$-caseína e de proteínas totais, porém menor proporção de $\kappa$-caseína em comparação ao leite estável. A restrição de $30 \%$ do aporte energético a vacas confinadas não reduziu a produção leiteira, porém diminuiu a percentagem de albumina sérica bovina e a estabilidade no teste do álcool; neste caso, o leite instável e o estável não diferiram quanto às proteínas lácteas.

Termos para indexação: $\beta$-caseína, $\kappa$-caseína, confinamento, eletroforese, leite instável não ácido, teste do álcool.

\section{Electrophoretic characterization of proteins and milk stability of cows submitted to feeding restriction}

\begin{abstract}
The objective of this work was to evaluate the feeding restriction effects on milk yield and on its electrophoretic protein profile, and to relate them to milk stability to the alcohol test. Two experiments were carried out with Jersey cows: in the first one, the effect of $40 \%$ feed restriction was evaluated on semiconfined cows; in the second one, the effect of $30 \%$ reduction in total digestive nutrients was evaluated on confined cows. Protein fractions were determined by electrophoresis and their quantification was done by image analysis. Milk samples were classified according to their stability in the $72^{\circ} \mathrm{GL}$-alcohol test. The $40 \%$ feed restriction for semiconfined cows decreased milk yield, but it did not change milk protein contents and stability; in this case, unstable milk showed larger contents of $\beta$-casein and total proteins, but lower $\kappa$-casein in comparison to stable milk. The $30 \%$ restriction of energy supply for confined cows did not reduce milk yield, but decreased the percentage of serum bovine albumin and milk stability; in this case, unstable and stable milk did not differ as for protein fractions.
\end{abstract}

Index terms: $\beta$-casein, $\beta$-casein, confinement, electrophoresis, unstable nonacid milk, alcohol test.

\section{Introdução}

As empresas de laticínio buscam leite cru com elevada qualidade e adequada estabilidade térmica. No entanto, a baixa estabilidade térmica do leite, estimada pelo teste do álcool, é um problema grave e frequente, encontrado em vários estados do Brasil (Marques et al., 2007; Zanela et al., 2009; Oliveira et al., 2011). A ocorrência de leite instável nas unidades de produção leiteira tem gerado descarte de matéria prima passível de ser industrializada, e atritos entre produtores de leite e indústria. Os produtores comumente não compreendem o que reduz a estabilidade do leite e, equivocadamente, a associam apenas à acidez excessiva (Marques et al., 2007).

Restrição alimentar e desequilíbrios nutricionais, frequentemente observados em rebanhos bovinos comerciais (Carvalho et al., 2006), reduzem a 
produção leiteira, os percentuais de proteína e caseína (O’Brien et al., 1999; Guinard-Flamend et al., 2007), a estabilidade do leite no teste do álcool (Zanela et al., 2006), e podem diminuir a acidez (Zanela et al., 2006; Marques et al., 2010) e reduzir (Marques et al., 2010) ou não afetar (Zanela et al., 2006) a densidade. O incremento do aporte nutricional, no entanto, aumenta a produção leiteira, os percentuais de proteína, lactose e caseína (O’Brien et al., 1999) e a estabilidade do leite, em vacas em estádio inicial ou médio de lactação (Marques et al., 2010).

Diferenças na estabilidade do leite, todavia, têm sido observadas em animais submetidos à restrição alimentar (Zanela et al., 2006). Essas diferenças podem estar relacionadas à composição da fração proteica do leite. Apesar disso, um limitado número de estudos tem averiguado a possível influência de proteínas do leite sobre sua estabilidade. Contudo, nem a correlação entre aporte alimentar e alteração no conteúdo de proteínas solúveis e insolúveis do leite, nem sua relação com a estabilidade do leite foram estudadas até o momento.

A proporção de א-caseína (Robitaille et al., 2001) e o polimorfismo genético das proteínas (Paterson et al., 1999) têm sido associados à estabilidade do leite. Michalcová \& Kruporá (2007) verificaram efeito negativo do alelo B na combinação fenotípica $\kappa$-caseína e $\beta$-lactoglobulina sobre a estabilidade no teste do álcool, ao contrário de Lopes (2008), que não encontrou diferenças nas frações proteicas entre o leite estável e instável, pelo teste do álcool, e de Botaro et al. (2007, 2009), que não observaram diferenças entre o leite instável e estável quanto ao polimorfismo da $\beta$-lactoglobulina e da $\kappa$-caseína. A contradição dos resultados quanto à composição das proteínas do leite e sua estabilidade, e o pequeno número de estudos que relacionam a variação do aporte alimentar com o conteúdo de proteínas solúveis e insolúveis no leite motivaram a realização do presente trabalho.

O objetivo deste trabalho foi avaliar os efeitos da restrição alimentar sobre a produção de leite bovino e sobre seu perfil eletroforético de proteínas, bem como relacioná-los à estabilidade do leite no teste do álcool.

\section{Material e Métodos}

Os animais foram selecionados do rebanho leiteiro do Sistema de Desenvolvimento e Pecuária Leiteira (Sispel), da Embrapa Clima Temperado, Pelotas, RS.
Foram realizados dois experimentos: no primeiro, avaliou-se o efeito da redução de $40 \%$ da alimentação, fornecida no cocho a vacas semiconfinadas; no segundo, avaliou-se o efeito da redução de $30 \%$ de nutrientes digestíveis totais, em vacas confinadas.

No primeiro experimento, de abril a agosto de 2008 , foram utilizadas seis vacas semiconfinadas da raça Jersey, em delineamento reversível, e cada vaca foi considerada uma unidade experimental. Ao início do estudo, as vacas produziam média diária de 16,4 $\pm 3,2 \mathrm{~L}$ de leite, encontravam-se com 48,3 $\pm 30,4$ dias de lactação, pesavam $382,4 \pm 15,39 \mathrm{~kg}$ e apresentavam 2,6 40,33 de escore de condição corporal (escala 1-5).

Durante o período pré-experimental de 15 dias, as vacas receberam $6,44 \mathrm{~kg}$ de ração concentrada e $4 \mathrm{~kg}$ de feno de alfafa por animal por dia, em dois arraçoamentos, além de sal mineral à vontade em cocho separado. A composição média do concentrado da dieta, nesse período foi de: sorgo em grão, $543 \mathrm{~g} \mathrm{~kg}^{-1}$; milho em grão, $177 \mathrm{~g} \mathrm{~kg}^{-1}$; farelo de soja $264 \mathrm{~g} \mathrm{~kg}^{-1}$; e $1,6 \mathrm{~g} \mathrm{~kg}^{-1}$ de fosfato bicálcico. Após a ordenha da manhã, todos os animais foram mantidos em pastagem de azevém anual (Lolium multiflorum) e aveia (Avena strigosa).

Durante o período experimental de 120 dias, as vacas receberam, alternadamente, a cada 30 dias, dieta controle, formulada para atender às exigências nutricionais de vacas com aproximadamente $400 \mathrm{~kg}$, para produção diária de $20 \mathrm{~L}$ de leite com $50 \mathrm{~g} \mathrm{~kg}^{-1} \mathrm{de}$ gordura (National Research Council, 2001); e dieta de restrição, constituída por $60 \%$ da alimentação fornecida no cocho, relativa à dieta controle. A dieta controle consistiu de: $412 \mathrm{~g} \mathrm{~kg}^{-1}$ de sorgo em grão; $470 \mathrm{~g} \mathrm{~kg}^{-1} \mathrm{de}$ casca de soja; $103 \mathrm{~g} \mathrm{~kg}^{-1}$ de farelo de soja; e $15 \mathrm{~g} \mathrm{~kg}^{-1} \mathrm{de}$ fosfato bicálcico. Foram fornecidos $6,44 \mathrm{~kg}$ de ração concentrada e $4 \mathrm{~kg}$ de feno de alfafa por animal, por dia, divididos em duas vezes, além de sal mineral à vontade em cocho separado. Entre os arraçoamentos, as vacas foram mantidas juntas, em pastagem natural melhorada com sobressemeadura de aveia e azevém anual. As vacas foram divididas em dois grupos que, alternadamente, receberam as dietas: o grupo um, iniciou com a dieta controle; e o grupo dois, com a dieta de restrição (Tabela 1).

No segundo experimento, realizado de abril a maio de 2010, foram utilizadas 16 vacas da raça Jersey, confinadas em instalações tipo "free-stall", em delineamento inteiramente casualizado, em que as 
vacas receberam a dieta controle ou a dieta ajustada em $30 \%$ da quantidade de nutrientes digestíveis totais. Cada vaca foi considerada uma unidade experimental. Ao início do experimento, as vacas estavam, em média, com 210 dias de lactação, produziam 12 $\pm 2,30 \mathrm{~L}$ de leite e pesavam $420 \pm 62,4 \mathrm{~kg}$ de peso corporal.

Os períodos experimentais foram de 14 dias cada, tendo sido um pré-experimental e dois experimentais, o que resultou no total de 42 dias. No período pré-experimental, a dieta basal diária, fornecida a cada vaca, constituiu-se de $5 \mathrm{~kg}$ de ração concentrada,
$30 \mathrm{~kg}$ de silagem de sorgo e 1,5 $\mathrm{kg}$ de feno de alfafa. O concentrado fornecido continha $380 \mathrm{~g} \mathrm{~kg}^{-1}$ de soja em grão, $200 \mathrm{~g} \mathrm{~kg}^{-1}$ de milho em grão, $380 \mathrm{~g} \mathrm{~kg}^{-1}$ de farelo de arroz integral, $20 \mathrm{~g} \mathrm{~kg}^{-1}$ de mistura mineral-vitamínica, $8 \mathrm{~g} \mathrm{~kg}^{-1}$ de calcário calcítico e $12 \mathrm{~g} \mathrm{~kg}^{-1}$ de $\mathrm{NaCl}$ (Tabela 2). O ajuste da dieta foi realizado para atender às exigências nutricionais de vacas com $420 \mathrm{~kg}$ de peso vivo, com produção média diária de $12 \mathrm{~L}$ de leite com $60 \mathrm{~g} \mathrm{~kg}^{-1}$ de gordura, sem ganho de peso, e com 33 semanas de lactação (National

Tabela 1. Composição das dietas controle e de restrição, fornecidas às vacas Jersey semiconfinadas ${ }^{(1)}$, no primeiro experimento.

\begin{tabular}{|c|c|c|c|c|c|c|c|c|}
\hline \multirow[t]{3}{*}{ Composição } & \multicolumn{4}{|c|}{ Dieta controle } & \multicolumn{4}{|c|}{ Dieta de restrição } \\
\hline & In natura & Matéria seca & Fornecimento & Proporção da MS & In natura & Matéria seca & Fornecimento & Proporção da MS \\
\hline & --------------- & (kg por dia $)$ & ------------------- & $\left(\mathrm{g} \mathrm{kg}^{-1}\right)$ & ------------ & $--(\mathrm{kg}$ por dia $)$ & -------------------- & $\left(\mathrm{g} \mathrm{kg}^{-1}\right)$ \\
\hline & \multicolumn{8}{|c|}{ Ingredientes } \\
\hline Feno de alfafa ${ }^{(2)}$ & 4,00 & 3,50 & - & - & 2,40 & 2,11 & - & - \\
\hline Sorgo moído & 2,65 & 2,33 & - & - & 1,59 & 1,40 & - & - \\
\hline Casca de soja & 3,02 & 2,66 & - & - & 1,81 & 1,60 & - & - \\
\hline Farelo de soja & 0,66 & 0,58 & - & - & 0,40 & 0,35 & - & - \\
\hline \multirow[t]{2}{*}{ Fosfato bicálcico } & 0,09 & 0,085 & - & - & 0,05 & 0,047 & - & - \\
\hline & \multicolumn{8}{|c|}{ Nutrientes $^{(3)}$} \\
\hline Proteína & - & - & 1,71 & 186,1 & - & - & 1,03 & 186,1 \\
\hline FDN & - & - & 4,40 & 480,0 & - & - & 2,64 & 480,0 \\
\hline NDT (calculado) & - & - & 6,57 & 714,9 & - & - & 3,94 & 714,9 \\
\hline
\end{tabular}

${ }^{(1)}$ As vacas permaneceram durante o dia em pastagem de aveia (Avena strigosa) e azevém anual (Lolium multiflorum), que apresentou, em média, a seguinte composição: $309,1 \mathrm{~g} \mathrm{~kg}^{-1}$ de matéria seca; $13,4 \mathrm{~g} \mathrm{~kg}^{-1}$ de matéria mineral; 594,6 $\mathrm{g} \mathrm{kg}^{-1}$ de fibra em detergente neutro (FDN); 171,1 g kg-1 de proteína; $677,1 \mathrm{~g} \mathrm{~kg}^{-1}$ de digestibilidade in vitro da matéria seca e nutrientes digestíveis totais (NDT) calculados de $692,8 \mathrm{~g} \mathrm{~kg}^{-1}$. ${ }^{(2)} \mathrm{Feno} \mathrm{de}$ alfafa: $921,9 \mathrm{~g}^{\mathrm{kg}}{ }^{-1} \mathrm{de}$ matéria seca; 98,2 $\mathrm{g} \mathrm{kg}^{-1}$ de matéria mineral; 502,0 $\mathrm{g} \mathrm{kg}^{-1}$ de FDN; 215,0 $\mathrm{g} \mathrm{kg}^{-1}$ de proteína; 700,8 $\mathrm{g} \mathrm{kg}^{-1}$ de NDT calculado de 714,7 $\mathrm{g} \mathrm{kg}^{-1} \cdot{ }^{(3)}$ Expressos em termos de matéria seca (MS).

Tabela 2. Composição nutricional e ingredientes das dietas controle e restrição, fornecidas a vacas Jersey confinadas, no segundo experimento.

\begin{tabular}{|c|c|c|c|c|c|c|c|c|}
\hline \multirow[t]{2}{*}{ Composição } & \multicolumn{4}{|c|}{ Dieta controle } & \multicolumn{4}{|c|}{ Dieta de restrição } \\
\hline & In natura & $\begin{array}{l}\text { Matéria seca } \\
\text { - (kg por dia) - }\end{array}$ & Fornecimento & $\begin{array}{c}\text { Proporção da MS } \\
\left(\mathrm{g} \mathrm{kg}^{-1}\right)\end{array}$ & In natura & $\begin{array}{r}\text { Matéria seca } \\
--(\mathrm{kg} \text { por dia })\end{array}$ & Fornecimento & $\begin{array}{c}\text { Proporção da MS } \\
\qquad\left(\mathrm{g} \mathrm{kg}^{-1}\right)\end{array}$ \\
\hline & \multicolumn{8}{|c|}{ Ingredientes } \\
\hline Silagem de sorgo & 30 & 8,21 & - & - & 21 & 5,74 & - & - \\
\hline Feno de alfafa & 1,5 & 1,32 & - & - & 3,4 & 2,99 & - & - \\
\hline Milho moído & 1,60 & 1,41 & - & - & 1,60 & 1,41 & - & - \\
\hline Farelo de trigo & 1,08 & 0,95 & - & - & 3,41 & 2,99 & - & - \\
\hline Farelo de arroz & 0,60 & 0,52 & - & - & 3,4 & 2,99 & - & - \\
\hline Farelo de girassol & 0,40 & 0,35 & - & - & - & - & - & - \\
\hline \multirow[t]{2}{*}{ Calcário calcítico } & - & - & - & - & 0,11 & 0,10 & - & - \\
\hline & \multicolumn{8}{|c|}{ Nutrientes $^{(1)}$} \\
\hline Matéria seca & - & - & 12,76 & - & - & - & 16,22 & \\
\hline Proteína & - & - & 1,44 & 113 & - & - & 2,11 & 130 \\
\hline NDT (calculado) & - & - & 7,96 & 624 & - & - & 10,22 & 630 \\
\hline Cálcio & - & - & 0,052 & 4,1 & - & - & 0,107 & 6,6 \\
\hline Fósforo & - & - & 0,045 & 3,5 & - & - & 0,060 & 3,7 \\
\hline
\end{tabular}

${ }^{(1)}$ Expressos em termos de matéria seca (MS). 
Research Council, 2001). O fornecimento da dieta foi realizado após as ordenhas da manhã e da tarde.

No início e no final de cada período experimental, foram registrados o peso e o estado de condição corporal, além da produção de leite, e foram coletadas amostras de leite nas ordenhas da manhã e a tarde, que foram mantidas resfriadas e, posteriormente, misturadas à produção leiteira, para formar uma amostra composta por animal. Foram determinados: a estabilidade do leite no teste do álcool, com concentrações de etanol na solução alcoólica de $68^{\circ}$ até $80^{\circ} \mathrm{GL}$ (Zanela et al., 2006); o pH; e a acidez titulável (Tronco, 1997). Uma alíquota das amostras de leite foi utilizada para a determinação da composição da fração proteica por eletroforese.

As amostras de leite compostas, destinadas à eletroforese, foram congeladas e mantidas em freezer a $-20^{\circ} \mathrm{C}$ até o momento da realização da análise. $\mathrm{Na}$ preparação das amostras, o leite foi descongelado lentamente, a $8^{\circ} \mathrm{C}$, e desnatado por centrifugação a $2.100 \mathrm{~g}$ por $30 \mathrm{~min}$ a $32^{\circ} \mathrm{C}$. Posteriormente, as amostras foram liofilizadas e acondicionadas em freezer a $-20^{\circ} \mathrm{C}$, até o momento da realização da eletroforese (Egito et al., 2006). Para a avaliação do perfil eletroforético das proteínas, utilizou-se uma cuba para eletroforese vertical Hoefer SE 600 standard dual cooled (Amersham Pharmacia Biotech). A SDS-page foi realizada com géis à concentração de $4,9 \%$, em $125 \mathrm{mmol} \mathrm{L}^{-1}$ de tampão Tris-HCl, pH 6,8, e com géis de separação com $15,4 \%$ de poliacrilamida, em $380 \mathrm{mmol} \mathrm{L}^{-1}$ de tampão Tris- $\mathrm{HCl}$, pH 8,8, com $0,1 \%$ de SDS. As amostras $\left(2 \mathrm{mg} \mathrm{mL}^{-1}\right)$ foram dissolvidas em tampão Tris-HCl, pH 6,8, com $0,1 \%$ de SDS e $5 \%$ de $\beta$-mercaptoetanol. Em seguida, foram aquecidas a $100^{\circ} \mathrm{C}$ por $3 \mathrm{~min}$, e $20 \mu \mathrm{L}$ foram depositados nos géis (Egito et al., 2006).

Após a corrida, as proteínas foram fixadas no gel com $12 \%$ de ácido tricloroacético (TCA) durante 30 min e, em seguida, coradas com $0,1 \%$ de azul de Coomassie R250, dissolvido em uma mistura de $50 \%$ de etanol e $2 \%$ de TCA, durante $120 \mathrm{~min}$. A descoloração foi realizada durante uma noite, com uma solução a $30 \%$ de etanol e 7,5\% de ácido acético (Egito et al., 2006). Os géis foram escaneados e processados por análise de imagens (Gel-Pro Analyser, Versão 6.0, Media Cybernetics, Bethesda, MD, EUA.), para quantificar a densidade óptica de cada fração proteica. $\mathrm{O}$ resultado da percentagem de cada faixa de eletroforese (fração proteica) foi calculado com base em $100 \%$ da densidade óptica do total da corrida, tendose descontado o background (fundo sem coloração) na coluna. Foi utilizado o marcador de peso molecular padrão (Bio-Rad, Hercules, CA, USA), para identificar o peso molecular das frações de proteínas que continham miosina $(200,0 \mathrm{kDa}), \beta$-galactosidase $(116,2 \mathrm{kDa})$, fosforilase $b \quad(97,4 \mathrm{kDa})$, soro albumina bovina $(66,2 \mathrm{kDa})$, ovalbumina $(45,0 \mathrm{kDa})$, anidrase carbônica $(31,0 \mathrm{kDa})$, inibidor de tripsina $(21,5 \mathrm{kDa})$, lisozima $(14,5 \mathrm{kDa})$, e aprotinina $(6,5 \mathrm{kDa})$. As bandas identificadas, selecionadas e quantificadas das proteínas do leite, obtidas por densitometria, foram: lactoferrina; albumina sérica bovina; imunoglobulina sérica de cadeia pesada; frações de caseína (CN) $\alpha_{\mathrm{S}}-\mathrm{CN}: \alpha_{\mathrm{S} 1}+\alpha_{\mathrm{S} 2}$, $\beta-\mathrm{CN}, \kappa-\mathrm{CN}$; e as proteínas solúveis $\beta$-lactoglobulina e $\alpha$-lactoalbumina. Os valores de proteína total e da caseína total foram calculados, respectivamente, como o somatório do resultado da densitometria das proteínas solúveis e insolúveis, e apenas das caseínas.

A análise estatística do primeiro experimento considerou o delineamento reversível com dois grupos, tendo-se avaliado os efeitos de dieta (controle e restrição, $\mathrm{n}=2$ ) e período $(\mathrm{n}=4)$. Os dados foram submetidos à análise de variância, e a comparação de médias foi feita pelo DMS de Fischer a 5\% de probabilidade, pelos procedimentos GLM e LSMeans, e a associação entre as variáveis foi feita pela correlação linear com o coeficiente de Pearson, pelo procedimento Corr (SAS Institute, 1999).

$\mathrm{Na}$ análise estatística do segundo experimento, considerou-se o delineamento experimental inteiramente casualizado, tendo-se avaliado o efeito dieta (controle e restrição, $n=2$ ). $O$ teste de médias utilizado foi o t-pareado, com o procedimento t-test, e a associação entre as variáveis foi feita pela correlação linear, com o coeficiente de Pearson determinado pelo procedimento Corr.

Adicionalmente, analisou-se a composição proteica do leite conforme sua estabilidade no teste do álcool. Considerou-se, separadamente, cada experimento, tendo as amostras de leite sido classificadas como instáveis, quando coagularam no teste do álcool em concentrações de etanol menores ou iguais a $72^{\circ} \mathrm{GL}$; as demais amostras foram consideradas estáveis. Os dados de composição proteica foram submetidos à análise de variância, em delineamento inteiramente casualizado, tendo-se considerado o efeito de estabilidade (leite estável e leite instável, $\mathrm{n}=2$ ). 


\section{Resultados e Discussão}

A restrição de $40 \%$ da alimentação fornecida no cocho a vacas semiconfinadas reduziu a produção leiteira em 15,5\%, mas não alterou características físicas como $\mathrm{pH}$, acidez titulável e estabilidade do leite no teste do álcool, nem a composição proteica do leite (Tabela 3). A concentração mínima de etanol que provocou coagulação das caseínas, no teste do álcool, foi inversamente relacionada à concentração de $\beta$-caseína $(\mathrm{r}=-0,50, \mathrm{p}<0,05, \mathrm{n}=24)$ e ao teor de proteína total do leite $(r=-0,45, p<0,05, n=24)$. As amostras de leite instáveis apresentaram maiores concentrações de $\beta$-caseína e de proteína total, mas menores valores de $\kappa$-caseína, comparadas ao leite estável (Tabela 4).

Tabela 3. Valores médios de produção de leite, características físicas e composição da fração proteica do leite ${ }^{(1)}$ de vacas Jersey semiconfinadas, no primeiro experimento.

\begin{tabular}{|c|c|c|c|}
\hline \multirow[t]{2}{*}{ Variável } & \multicolumn{2}{|c|}{ Dieta } & \multirow[t]{2}{*}{$\mathrm{p}$} \\
\hline & Controle & Restrição & \\
\hline Produção de leite (L por dia) & 14,34 & 12,42 & 0,0167 \\
\hline Estabilidade ${ }^{(2)}$ & 74,67 & 72,50 & 0,1170 \\
\hline $\mathrm{pH}$ & 6,82 & 6,83 & 0,7427 \\
\hline Acidez titulável ${ }^{(3)}$ & 15,85 & 14,87 & 0,1815 \\
\hline$\alpha$ caseína $(\mathrm{s} 1+\mathrm{s} 2)$ & 34,19 & 35,18 & 0,5028 \\
\hline$\beta$ caseína & 28,06 & 29,12 & 0,5810 \\
\hline$\kappa$ caseína & 2,27 & 1,77 & 0,1672 \\
\hline$\alpha$ lactoalbumina & 3,24 & 3,02 & 0,7393 \\
\hline$\beta$ lactoglobulina & 17,03 & 15,85 & 0,3724 \\
\hline Lactoferrina & 0,61 & 0,65 & 0,8097 \\
\hline Albumina sérica bovina & 0,82 & 0,92 & 0,4849 \\
\hline Imunoglobulina & 1,10 & 1,18 & 0,5950 \\
\hline Proteína total ${ }^{(4)}$ & 88,40 & 88,90 & 0,6759 \\
\hline Caseína total ${ }^{(4)}$ & 64,80 & 65,46 & 0,5988 \\
\hline Caseína:proteína & 73,18 & 73,61 & 0,7952 \\
\hline
\end{tabular}

${ }^{(1)}$ Expressa como percentual de proteína total do leite. ${ }^{(2)}$ Estabilidade no teste do álcool, expressa como a menor concentração de álcool $\left(\mathrm{V} \mathrm{V}^{-1}\right)$ na mistura que tenha provocado coagulação do leite. ${ }^{(3)}$ Acidez titulável, em graus Dornic. ${ }^{(4)}$ Expressos como percentual do nitrogênio total do leite.

Tabela 4. Valores percentuais de $\beta$-caseína, $\kappa$-caseína e proteína total do leite de vacas Jersey semi-confinadas, no primeiro experimento.

\begin{tabular}{|c|c|c|c|}
\hline \multirow[t]{2}{*}{ Variável } & \multicolumn{2}{|c|}{ Estabilidade $^{(1)}$} & \multirow[t]{2}{*}{$\mathrm{p}$} \\
\hline & Instável & Estável & \\
\hline$\beta$-caseína & 30,56 & 26,92 & 0,0405 \\
\hline$\kappa$-caseína & 1,83 & 2,67 & 0,0681 \\
\hline Proteína total & 89,80 & 87,74 & 0,0315 \\
\hline
\end{tabular}

${ }^{(1)}$ Percentagem de álcool $\left(\mathrm{V} \mathrm{V}^{-1}\right)$ na mistura que tenha provocado a coagulação do leite.
A restrição de $30 \%$ do aporte energético a vacas confinadas reduziu o $\mathrm{pH}$, a estabilidade do leite no teste do álcool e a proporção de albumina sérica bovina, mas não alterou a produção e as demais frações proteicas do leite (Tabela 5). A concentração mínima de etanol capaz de causar a coagulação das caseínas no teste do álcool não foi correlacionada a qualquer das frações proteicas. Não houve diferenças entre as amostras de leite instável e estável, quanto à proporção das frações proteicas.

A redução da produção leiteira, em consequência da restrição de $40 \%$ na alimentação, em vacas semiconfinadas, está relacionada ao menor aporte nutricional; todavia, sua magnitude apenas moderada pode ser explicada, em parte, por um provável consumo compensatório de pasto, embora não se tenha avaliado isto. Essa inferência encontra suporte na redução apenas moderada na produção leiteira $(15,5 \%)$, na ausência de efeito da restrição alimentar sobre o peso corporal - respectivamente de 388,6 e $386,5 \mathrm{~kg}$, para as dietas controle e restrição -, e o estado de condição corporal - respectivamente de 2,33 e 2,45. Esse resultado está de acordo com Guinard-Flamend et al. (2007), que reportaram que restrições de 20 a $40 \%$ na alimentação fornecida reduziram a produção leiteira entre 15 e $25 \%$. Contudo, em estudos com

Tabela 5. Valores médios da produção de leite, características físicas e composição da fração proteica do leite ${ }^{(1)}$ de vacas Jersey, no segundo experimento.

\begin{tabular}{|c|c|c|c|}
\hline \multirow[t]{2}{*}{ Variável } & \multicolumn{2}{|c|}{ Dieta } & \multirow[t]{2}{*}{$\mathrm{p}$} \\
\hline & Controle & Restrição & \\
\hline Produção de leite (L por dia) & 9,79 & 9,72 & 0,8295 \\
\hline Estabilidade $^{(2)}$ & 76,01 & 72,75 & 0,0014 \\
\hline $\mathrm{pH}$ & 6,80 & 6,75 & 0,0312 \\
\hline Acidez titulável ${ }^{(3)}$ & 16,94 & 16,75 & 0,6175 \\
\hline$\alpha$-caseína $(\mathrm{s} 1+\mathrm{s} 2)$ & 45,68 & 44,80 & 0,7237 \\
\hline$\beta$-caseína & 15,76 & 16,66 & 0,5405 \\
\hline$\kappa$-caseína & 3,87 & 3,60 & 0,4925 \\
\hline$\alpha$-lactoalbumina & 3,12 & 3,48 & 0,4432 \\
\hline$\beta$-lactoglobulina & 11,54 & 12,52 & 0,2951 \\
\hline Lactoferrina & 1,23 & 1,23 & 0,9783 \\
\hline Albumina sérica bovina & 2,04 & 1,40 & 0,0426 \\
\hline Imunoglobulina & 1,87 & 1,28 & 0,1949 \\
\hline Proteína total ${ }^{(4)}$ & 89,96 & 90,80 & 0,4326 \\
\hline Caseína total $^{(4)}$ & 62,99 & 64,02 & 0,5283 \\
\hline Caseína:proteína & 70,02 & 70,51 & 0,7434 \\
\hline
\end{tabular}

${ }^{(1)}$ Expressa como percentual de proteína total do leite. ${ }^{(2)}$ Estabilidade no teste do álcool, expressa como a menor concentração de álcool $\left(\mathrm{V} \mathrm{v}^{-1}\right)$ na mistura que tenha provocado coagulação do leite. ${ }^{(3)}$ Acidez titulável, em graus Dornic. ${ }^{(4)}$ Expressos como percentual do nitrogênio total do leite. 
vacas submetidas a 40 e $50 \%$ de restrição alimentar, a magnitude da redução da produção leiteira foi maior (Zanela et al., 2006; Fruscalso, 2007), o que pode estar relacionado ao estádio lactacional mais precoce, à menor condição corporal e à impossibilidade de consumo compensatório da pastagem, nesses estudos.

A restrição de $30 \%$ do aporte energético em vacas confinadas, no entanto, não reduziu sua produção leiteira, o que pode estar relacionado a seu avançado estádio lactacional, já que essas vacas se encontravam com mais de 230 dias de lactação. Isso pode ter causado diminuição na capacidade de resposta das vacas à alimentação, pela redução no número de células epiteliais mamárias e pelo aumento da taxa de apoptose (Capuco et al., 2001), observada em vacas sob restrição alimentar (Dessauge et al., 2011).

A restrição de $40 \%$ na alimentação fornecida a vacas semiconfinadas não teve efeito sobre a estabilidade do leite no teste do álcool (Tabela 3), o que discorda dos resultados obtidos pela restrição de $30 \%$ no aporte energético a vacas confinadas, observados no presente trabalho (Tabela 4). Tal resultado discorda, também, dos de Hernández \& Ponce (2006), Zanela et al. (2006) e Fruscalso (2007).

A relação entre restrição alimentar e redução da estabilidade do leite ainda não foi completamente explicada; porém, há evidência de que o estresse causado pela restrição pode provocar aumento da permeabilidade das junções firmes entre as células epiteliais mamárias e, com isso, a maior passagem de cátions monovalentes provenientes do sangue, o que aumentaria a força iônica e diminuiria a repulsão entre as micelas, o que teria efeito favorável à coagulação (Stumpf, 2012).

No presente trabalho, a restrição alimentar não alterou o perfil eletroforético das proteínas do leite, exceto pela redução observada na albumina sérica bovina. O incremento da albumina sérica bovina é usualmente associado ao aumento da permeabilidade dos capilares ou das junções das células epiteliais mamárias, provocados por prolongamento do intervalo entre ordenhas (Bernier-Dodier et al., 2010) e por inflamação ou infecção do úbere (Litwinczuk et al., 2011). Entretanto, no presente trabalho, não houve diferença quanto à contagem de células somáticas, em leite de vacas confinadas que receberam a dieta controle e a dieta com restrição de $30 \%$ no aporte energético, respectivamente de $5,49 \pm 0,68$ e 5,31 $\pm 0,56$ células.
Guinard-Flamend et al. (2007) observaram que restrição alimentar de $30 \%$ reduziu o percentual de caseína, mas não alterou o percentual de soro-proteínas lácteas. Dessauge et al. (2011) observaram menor expressão da transcrição de $\alpha$-lactoalbumina e $\kappa$-caseína, em vacas submetidas à restrição alimentar.

Quanto à composição proteica do leite, os resultados estão de acordo com os de Fruscalso (2007), em que a restrição alimentar não causou alteração no teor de proteína do leite; porém, diferem de dados relativos à redução no teor de proteína total, provocada por restrição na alimentação oferecida (O'Brien et al., 1999; Zanela et al., 2006; Guinard-Flamend et al., 2007), e de dados relativos à proteína metabolizável na dieta (Hernández \& Ponce, 2006), ou ao aumento no teor de proteína total observado com o maior aporte de nutrientes na dieta (Marques et al., 2010).

Bartsch et al. (1979) verificaram que a proporção das frações $\beta$-lactoglobulina e $\alpha$-lactoalbumina, em relação à proteína total, não se alteraram e tampouco mostraram relação com a estabilidade térmica do leite, dados corroborados pelo presente trabalho. A ausência de efeito da restrição alimentar sobre o percentual de proteína total do leite, verificada no presente trabalho, corrobora também os resultados de Fruscalso (2007). Porém, discorda dos resultados de O'Brien et al. (1999), Zanela et al. (2006) e Guinard-Flamend et al. (2007), que encontraram redução no teor de proteína total no leite, após submeterem vacas à restrição da quantidade de alimentos ou de proteína metabolizável na dieta (Hernández \& Ponce, 2006). Além disso, Marques et al. (2010) verificaram aumento no teor de proteína total no leite, ao fornecer maior aporte de nutrientes na dieta. O'Brien et al. (1999) observaram que a oferta reduzida de pasto reduziu a estabilidade do leite no teste do álcool, e os teores de proteína total e de caseína. Esses autores também verificaram aumento de plasmina, uma protease que degrada especialmente a $\beta$-caseína, no leite de vacas mantidas sob oferta reduzida de pasto.

A relação negativa encontrada entre $\beta$-caseína e estabilidade do leite no teste do álcool, e o maior percentual dessa proteína no leite instável (Tabela 4) contradizem os resultados de Silanikove et al. (2000, 2009). Segundo esses autores, a $\beta$-caseína é degradada pela plasmina, em condições de estresse ou restrição alimentar (O'Brien et al., 1999), o que gera o peptídeo 1-28 ( $\gamma$-caseína) que, por sua vez, bloqueia os 
canais de potássio junto à membrana apical das células epiteliais mamárias e reduz a síntese do leite e de seus componentes.

Além disso, a maior concentração da $\kappa$-caseína no leite estável está em concordância com os resultados de Robitaille et al. (2001). Fox \& Brodkorb (2008) destacam a ação estabilizante da kappa-caseína, ao realizar a interface entre o interior da micela, onde se concentram as caseínas mais hidrofóbicas, e o ambiente aquoso, o que atua como uma barreira física e eletrostática à agregação. Entretanto, o resultado deste trabalho discorda dos descritos por Botaro et al. (2007) e Lopes (2008), que não verificaram diferenças no percentual de $\kappa$-caseína entre leite estável e instável.

\section{Conclusões}

1. A restrição de $40 \%$ na alimentação reduz a estabilidade do leite e a produção leiteira, mas não altera a composição da fração proteica do leite.

2. Amostras de leite instáveis ao teste do álcool apresentam menor concentração de $\kappa$-caseína e maiores concentrações de $\beta$-caseína e de proteínas totais.

3. A restrição de $30 \%$ do aporte energético a vacas confinadas e em estádio avançado de lactação não reduz a produção leiteira, porém diminuiu a percentagem de albumina sérica bovina e a estabilidade do leite; neste caso, o leite instável e o estável não diferem quanto à proporção das frações protéicas.

\section{Agradecimentos}

À Coordenação de Aperfeiçoamento de Pessoal de Nível Superior, por concessão de bolsa.

\section{Referências}

BARTSCH, B.D.; GRAHAM, E.R.B.; MCLEAN, M.D. Protein and fat composition and some manufacturing properties of milk from dairy cows fed on hay and concentrate in various ratios. Australian Journal of Agricultural Research, v.30, p.191-199, 1979.

BERNIER-DODIER, P.; DELBECCHI, L.; WAGNER, G.F.; TALBOT, B.G.; LACASSE, P. Effect of milking frequency on lactation persistency and mammary gland remodeling in mid-lactation cows. Journal of Dairy Science, v.93, p.555-564, 2010.

BOTARO, B.G.; LIMA, Y.V.R. de; AQUINO, A.A.; FERNANDES, R.H.R.; GARCIA, J.F.; SANTOS, M.V. dos. Polimorfismo da beta-lactoglobulina não afeta as características físico-químicas e a estabilidade do leite bovino. Pesquisa Agropecuária Brasileira, v.42, p.747-753, 2007.

BOTARO, B.G.; LIMA, Y.V.R. de; CORTINHAS, C.S.; SILVA, L.F.P. e; RENNÓ, F.P.; SANTOS, M.V. Effect of the kappa-casein gene polymorphism, breed and seasonality on physicochemical characteristics, composition and stability of bovine milk. Revista Brasileira de Zootecnia, v.38, p.2447-2454, 2009.

CAPUCO, A.V.; WOOD, D.L.; BALDWIN, R. Mammary cell number, proliferation, and apoptosis during a bovine lactation: relation to milk production and effect of bST. Journal of Dairy Science, v.84, p.2177-2187, 2001.

CARVALHO, P.C. de F.; FISCHER, V.; SANTOS, D.T. dos; RIBEIRO, A.M.L.; QUADROS, F.L.F. de; CASTILHOS, Z.M.S.; POLI, C.H.E.C.; MONTEIRO, A.L.G.; NABINGER, C.; GENRO., T.C.M.; JACQUES, A.V.A. Produção animal no bioma Campos sulinos. Brazilian Journal of Animal Science, v.35, p.156-202, 2006.

DESSAUGE, F.; LOLlIVIER, V.; PONCHON, B.; BRUCKMAIER, R.; FINOT, L.; WIANT, S.; CUTULIC, G.; DISEHAUS, C.; BARBEY, S.; BOUTINANAUD, N.Y. Effects of nutrient restriction on mammary cell turnover and mammary gland remodeling in lactating dairy cows. Journal of Dairy Science, v.94, p.4623-4635, 2011.

EGITO, A.S.; ROSINHA, G.M.S.; LAGUNA, L.E.; MICLO, L.; GIRARDET, J.M.; GAILLARD, J.L. Método eletroforético rápido para detecção da adulteração do leite caprino com leite bovino. Arquivos Brasileiro de Medicina Veterinária e Zootecnia, v.58, p.932-939, 2006.

FOX, P.F.; BRODKORB, A. The casein micelle: historical aspects, current concepts and significance. International Dairy Journal, v.18, p.677-684, 2008.

FRUSCALSO, V. Influência da oferta da dieta, ordem e estádio de lactação sobre as propriedades físico-químicas e microbiológicas do leite bovino e a ocorrência do leite instável não ácido. 2007. 132p. Dissertação (Mestrado) - Universidade Federal do Rio Grande do Sul, Porto Alegre.

GUINARD-FLAMEND, J.; DELAMAIRE, E.; LAMBERTON, P.; PEYRAUD, J.L. Adaptations of mammary uptake and nutrient use to one-daily milking and feed restriction in dairy cows. Journal of Dairy Science, v.90, p.5062-5072, 2007.

HERNÁNDEZ, R.; PONCE, P. Efecto de tres tipos de dieta sobre la aparición de trastornos metabólicos y su relación con alteraciones en la composición de la leche en vacas Holstein Friesian. Revista Salud Animal, v.28, p.13-20, 2006.

LITWINCZUK, Z.; KRÓL, J.; BRODZIAK, A.; BARLOWSKA, J. Changes of protein content and its fractions in bovine milk from different breeds subject to somatic cell count. Journal of Dairy Science, v.94, p.684-691, 2011.

LOPES, L.C. Composição e características físico-químicas do leite instável não ácido (LINA) na região de Casa Branca, Estado de São Paulo. 2008. 63p. Dissertação (Mestrado) Universidade de São Paulo, Pirassununga. 
MARQUES, L.T.; FISCHER, V.; ZANELLA, M.B.; RIBEIRO, M.E.R.; STUMPF JUNIOR, W.; MANZKE, N. Fornecimento de suplementos com diferentes níveis de energia e proteína para vacas Jersey e seus efeitos sobre a instabilidade do leite. Revista Brasileira de Zootecnia, v.39, p.2724-2730, 2010.

MARQUES, L.T.; ZANELA, M.B.; RIBEIRO, M.E.R.; STUMPF JÚNIOR, W.; FISCHER, V. Ocorrência do leite instável ao álcool $76 \%$ e não ácido (LINA) e efeito sobre os aspectos físico-químicos do leite. Revista Brasileira de Agrociência, v.13, p.91-97, 2007.

MICHALCOVÁ, A.; KRUPOVÁ, Z. Influence of composite $\mathrm{K}$-casein and $\beta$-lactoglobulin genotypes on composition, rennetability and heat stability of milk of cows of Slovak Pied breed. Czech Journal of Animal Science, v.52, p.292-298, 2007.

NATIONAL RESEARCH COUNCIL. Nutrient requirements of dairy cattle. $7^{\text {th }}$ ed. Whashinton: National Academy, 2001. 381p.

O’BRIEN, B.; DILLON, P.; MURPHY, J.J.; MEHRA, R.K.; GUINEE, T.P.; CONNOLLY, J.F.; KELLY, A.; JOYCE, P. Effects of stocking density and concentrate supplementation of grazing dairy cows on milk production, composition and processing characteristics. Journal of Dairy Research, v.66, p.165-176, 1999.

OLIVEIRA, C.A.F. de; LOPES, L.C.; FRANCO, R.C.; CORASSIN, C.H. Composição e características físico-químicas do leite instável não ácido recebido em laticínio do Estado de São Paulo, Brasil. Revista Brasileira de Saúde e Produção Animal, v.12, p.508-515, 2011

PATERSON, G.R.; MACGIBBON, A.K.H.; HILL, J.P. Influence of kappa-casein and beta-lactoglobulin phenotype on the heat stability of milk. International Dairy Journal, v.9, p.375-376, 1999.
ROBITAILlE, G.; BRITTEN, M.; PETITCLERC, D. Effect of a differential allelic expression of kappa-casein gene on ethanol stability of bovine milk. Journal of Dairy Research, v.68, p.145-149, 2001.

SAS INSTITUTE. SAS/STAT user's guide. Version 8. Cary: SAS Institute, 1999. 3809p.

SILANIKOVE, N.; SHAMAY, A.; SHINDER, D.; MORAN, A. Stress down regulates milk yield in cows by plasmin induced beta-casein product that blocks $\mathrm{K}+$ channels on the apical membranes. Life Sciences, v.67, p.2201-2212, 2000.

SILANIKOVE, N.; SHAPIRO, F.; SHINDER, D. Acute heat stress brings down milk secretion in dairy cows by up-regulating the activity of the milk-borne negative feedback regulatory system. BioMed Central Physiology, v.9, 2009. Doi:10.1186/1472-6793-9-13.

STUMPF, M.T. Uso de aditivos e variação do aporte de alimentos na dieta de vacas em lactação sobre a composição e estabilidade do leite. 2012. 68p. Dissertação (Mestrado) - Universidade Federal do Rio Grande do Sul, Porto Alegre.

TRONCO, V.M. Manual para inspeção da qualidade do leite. Santa Maria: Universidade de Santa Maria, 1997. 166p.

ZANELA, M.B.; FISCHER, V.; RIBEIRO, M.E.R.; BARBOSA, R.S.; MARQUES, L.T.; STUMPF JÚNIOR, W.; ZANELA, C. Leite instável não-ácido e composição do leite de vacas Jersey sob restrição alimentar. Pesquisa Agropecuária Brasileira, v.41, p.835-840, 2006.

ZANELA, M.B.; RIBEIRO, M.E.R.; FISCHER, V.; GOMES, J.F.; STUMPF JÚNIOR, W. Ocorrência do leite instável não ácido no noroeste do Rio Grande do Sul. Arquivo Brasileiro de Medicina Veterinária e Zootecnia, v.61, p.1009-1013, 2009.

Recebido em 18 de outubro de 2011 e aprovado em 22 de março de 2012 